\title{
Short Communication: Feed Selection by Dairy Cows Fed Individually in a Tie-Stall or as a Group in a Free-Stall Barn
}

\author{
C. Leonardi ${ }^{1}$ and L. E. Armentano ${ }^{2}$ \\ Department of Dairy Science, University of Wisconsin, Madison 53706
}

\section{ABSTRACT}

The objectives of the present study were to compare feed selection in tie- vs. free-stall barns and also to verify possible correlations between feed selection and milk composition. Forty multiparous and 20 primiparous lactating Holstein cows were utilized in a crossover design with 21 -d periods. Cows were randomly divided into 2 groups; group 1 was housed in a free-stall barn during period 1 and a tie-stall barn during period 2, and vice versa for group 2 . In the free-stall barn, 18 extra cows were also present. Animals were fed the same diet once daily in the free-stall barn at $1100 \mathrm{~h}$ and twice daily at 1100 and $1500 \mathrm{~h}$ in the tie-stall barn to obtain approximately $10 \%$ daily refusals in both facilities. Group feed selection in the free-stall barn was measured and compared with the group feed selection in the tie-stall barn, obtained by summing individual feed offered and refused. Feed selection was analyzed including treatment and period in the model. Sequence effect and true error were combined into a single degree of freedom error term. Intake of the longest particles expressed as a percentage of the predicted intake was $73.2 \%$ in a tie-stall barn and $63.3 \%$ in a free-stall barn. There were no significant correlations between individual feed selection measured in the tie-stall barn and milk composition. Feed selection estimates made with individually fed cows are likely to underestimate average feed selection in a free-stall barn.

Key words: feed selection, tie-stall barn, free-stall barn, dairy cow

In a previous experiment it was established that dairy cattle sort their diets (Leonardi and Armentano, 2003). In general, when fed a diet containing $40 \%$ forage and $60 \%$ concentrate (DM basis) cows sorted against longer particles in favor of shorter particles (Leonardi

Received August 16, 2006.

Accepted December 19, 2006.

${ }^{1}$ Present address: Department of Experimental Statistics, Louisiana State University, 161 Agric. Admin. Bldg., Baton Rouge, LA 70803.

${ }^{2}$ Corresponding author: learment@wisc.edu and Armentano, 2003). However, the degree of feed sorting behavior may vary across cows when measured in a tie-stall barn (Leonardi and Armentano, 2003; Leonardi et al., 2005). Feed selection by a cow that exhibits sorting behavior in a tie-stall barn is limited by the fact that the residual available feed becomes coarser during the feeding interval. In a free-stall facility, the same cows may move to fresh undisturbed feed or less sorted feed left by other cows. This is likely to increase not only the average but also the variance of feed selection. Therefore, the primary objective of the present study was to quantify changes in feeding behavior between cows in tie- and free-stall barns.

Previous investigations of feed selection used sampling periods that were too short to adequately evaluate the effect of feed selection on milk production and composition (Leonardi and Armentano, 2003) or only a tendency in increased milk fat percentage was observed by reducing feed selection against longer particles (Leonardi et al., 2005). The present study involved a large number of cows and was conducted over periods long enough for the consumed diet to affect milk composition. Because cows frequently consume diets with lower particle size than the diet offered (Leonardi and Armentano, 2003) and diets with low particle size can reduce milk fat concentration (Krause and Combs, 2003), we chose to measure the correlation between feed selection by the cows while in tie-stall housing and their milk composition.

Forty multiparous and 20 primiparous lactating Holstein cows were utilized in a crossover design with 21$\mathrm{d}$ periods. At the beginning of the study cows averaged $102 \pm 52$ (mean \pm SD) DIM and produced $37.7 \pm 7.4$ $\mathrm{kg}$ of milk daily. Cows within parity, primiparous or multiparous, were randomly divided in 2 groups composed of 10 primiparous and 20 multiparous cows each. Cows in group 1 were housed in the free-stall barn during period 1 and tie-stall barn during period 2 , and vice versa for group 2 . In the free-stall barn 18 extra cows were also present, 14 of which were identical in both periods. These nonexperimental cows were considered a random sample of the herd population. The Animal Care Committee of the College of Agricultural and 
Life Sciences of the University of Wisconsin-Madison approved all procedures involving animals. The freestall barn had 51 head locks and 50 stalls. Stalls were configured in 2 rows arranged tail to tail. All flooring outside the stalls area was concrete. Stalls were bedded with mattresses and sawdust in both barns.

The diet was the same for both facilities and consisted of $10.3 \%$ wheat straw, $30.2 \%$ alfalfa hay, $20.2 \%$ corn silage, $25.8 \%$ corn grain, $10.2 \%$ soybean meal, $2.1 \%$ roasted soybeans, and $1.2 \%$ mineral and vitamins (DM basis). The diet contained $68.0 \% \mathrm{DM}, 15.7 \% \mathrm{CP}, 32.7 \%$ $\mathrm{NDF}$, and $2.8 \%$ fatty acids. The diet was mixed once daily and cows were fed once daily at $1100 \mathrm{~h}$ in the free-stall barn and twice daily at 1100 and $1500 \mathrm{~h}$ in the tie-stall barn to obtain approximately $10 \%$ daily refusals in both facilities. In both barns feed was pushed up closer to the cows twice daily during milking. The diet was adjusted weekly to account for forage DM fluctuation. Feed samples were collected twice during the last $2 \mathrm{wk}$ of each experimental period, dried at $60^{\circ} \mathrm{C}$ for $48 \mathrm{~h}$, ground to pass through a 1-mm screen (Wiley mill, Arthur H. Thomas, Philadelphia, PA) and analyzed for DM, CP, NDF, and fatty acids as described in Leonardi et al. (2005). Cows were milked twice daily. Milk production was recorded, and milk was sampled at each milking during the last $3 \mathrm{~d}$ of each period in both barns. Milk samples were analyzed for protein, fat, and lactose by infrared analysis (AgSource Milk Analysis Laboratory, Menomonie, WI) with a Fossmatic-605 (Foss Electric, Hillerod, Denmark). Samples of tie- and free-stall barn diets were collected in duplicate during the last $3 \mathrm{~d}$ of each experimental period. In the tie-stall barn, individual orts samples were collected during d 19 and 20 of each period. In the free-stall barn orts were gathered together, and duplicate samples of the group orts were collected on $d 18,19,20$, and 21. Dietary and orts samples collected in both facilities were approximately $5 \mathrm{~L}$ each. Particle size distribution of diet and orts was determined by sieving as-fed diets using the UW particle size separator in accordance to the ASAE standard S424.1 protocol (ANSI, 1998). The separator has 5 square-holed screens $\left(\mathbf{Y}_{1}\right.$ to $\left.\mathbf{Y}_{5}\right)$ with diagonal openings of $26.9 \mathrm{~mm}$ for $\mathrm{Y}_{1}, 18 \mathrm{~mm}$ for $\mathrm{Y}_{2}$, $8.98 \mathrm{~mm}$ for $\mathrm{Y}_{3}, 5.61 \mathrm{~mm}$ for $\mathrm{Y}_{4}$, and $1.65 \mathrm{~mm}$ for $\mathrm{Y}_{5}$, and one pan. The percentage (mean \pm SD) of dietary particles retained on each screen was: $6.3 \pm 2.2 \%$ for $\mathrm{Y}_{1}, 9.7 \pm 1.8 \%$ for $\mathrm{Y}_{2}, 20.3 \pm 2.4 \%$ for $\mathrm{Y}_{3}, 9.6 \pm 0.7$ for $\mathrm{Y}_{4}, 24.8 \pm 2.3$ for $\mathrm{Y}_{5}$, and $29.3 \pm 3.6 \%$ for pan (on as-fed basis). Ration sorting for tie- and free-stall barn groups was calculated as described in Leonardi et al. (2005). Both tie- and free-stall barn intakes by screen were calculated as a group. Values below $100 \%$ indicate selective refusals, above $100 \%$ is preferential consumption, and equal to $100 \%$ is no feed selection.
Group values for the tie-stall barn were generated by adding individual cow feed offered and individual cow intake of each screen to generate data comparable with that available from cows fed as a group. Group feed selection within facility was analyzed utilizing the MIXED procedure of SAS (SAS Inst. Inc., Cary, NC). The model included treatment and period. In a previous experiment, where 2 diets were fed in a crossover design, there was no sequence effect on feed selection of any screen and there was a period effect on feed selection of $Y_{1}$ (Leonardi et al., 2005). Therefore, period effect was included in the model, and sequence effect and true error were combined into a single degree of freedom error term. Values reported are least squares means. Significance was declared at $P \leq 0.05$, and a trend was reported if $0.05<P \leq 0.10$. The Pearson moment correlation between feed selection and milk production, milk composition, and amount of orts reported as a percentage of feed offered was calculated utilizing the tie-stall data and the CORR procedure of SAS.

When fed a diet containing $68 \% \mathrm{DM}$, individually fed cows on average sorted against longer particles in favor of smaller particles (Figure 1). In particular, $20 \%$ of the cows ate less than $60 \%$ of their predicted intake of $Y_{1}$. The feed choice observed in the present study was similar to the one observed previously (Leonardi and Armentano, 2003; Leonardi et al., 2005). When cows were fed individually a diet containing $64 \% \mathrm{DM}, 28 \%$ of the cows ate less than $60 \%$ of their predicted intake of $\mathrm{Y}_{1}$ (Leonardi et al., 2005).

Feed selection against the $Y_{1}$ screen was greater in free-stall barn housing (Figure 2). Intake of $\mathrm{Y}_{1}$ as a percentage of the predicted intake was $73.2 \%$ for tieand $63.3 \%$ for free-stall barn $(P=0.03)$. Also, intake of $\mathrm{Y}_{5}$ as a percentage of the predicted intake was $105.6 \%$ for tie-stall and $107.8 \%$ for free-stall barns $(P=0.06)$. As previously stated, there were 18 nonexperimental cows present in the free-stall barn that were not included in the tie-stall barn data. Although these cows were a random sample of the barn population, it is possible that these 18 nonexperimental cows sorted to a greater extent than the group of cows on experiment and therefore may be responsible for the increased feed selection observed in the free-stall barn for $\mathrm{Y}_{1}$. To examine this possibility, we calculated the extent of feed selection of $Y_{1}$ that these 18 nonexperimental cows as a group should have done to be exclusively responsible for the difference between the tie- and free-stall barns. This was calculated assuming that the experimental cows behaved similarly in the free- and tie-stall barns, and therefore their intake of $Y_{1}$ as a percentage of predicted was $73.2 \%$ in both facilities. To decrease the freestall barn average from 73.2 to $63.3 \%$, average intake of $\mathrm{Y}_{1}$ as a percentage of predicted intake of the 18 nonex- 


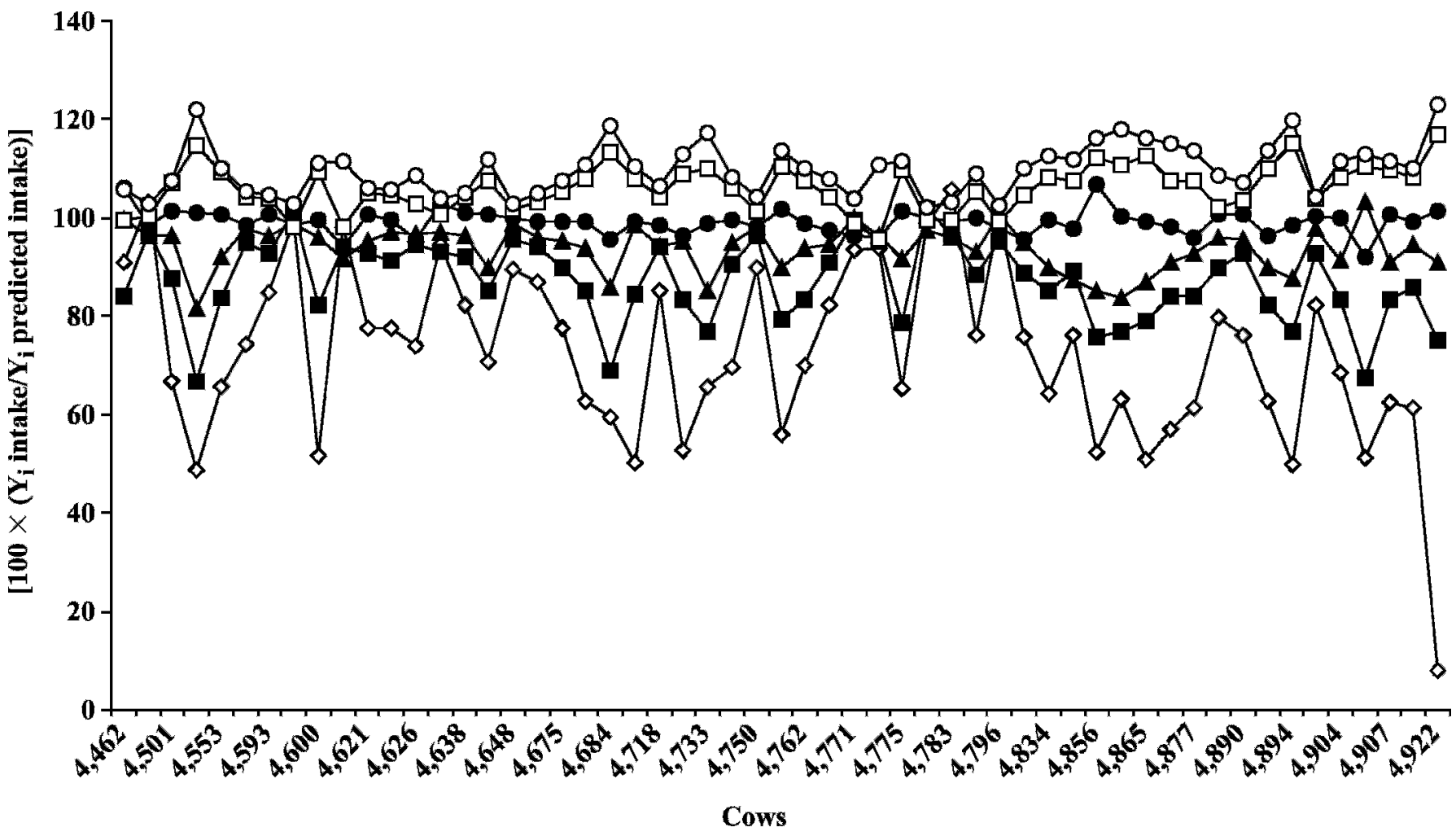

Figure 1. Cow variability for feed selection in tie-stall barn (as-fed basis) $21 \mathrm{~h}$ after morning feeding. Data are averaged across d 19 and 20 by cow and presented by screen. Screens are labeled from longer to finer particles as $\mathrm{Y}_{1}(\diamond), \mathrm{Y}_{2}(\boldsymbol{\square}), \mathrm{Y}_{3}(\boldsymbol{\Delta}), \mathrm{Y}_{4}(\bullet), \mathrm{Y}_{5}(\square)$, and pan (○), respectively.

perimental cows should have been $48 \%$. Utilizing the $\mathrm{SD}$ of the tie-stall barn, $\mathrm{Y}_{1}$ feed selection $95 \%$ CI of the experimental and nonexperimental groups in the freestall barn were calculated. The $\mathrm{Y}_{1}$ feed selection $95 \%$ CI was 65.8 to $80.6 \%$ for the group on trial and 38.8 to $57.2 \%$ for the nonexperimental 18 cows. Therefore, in order for the nonexperimental cows to be solely responsible for the difference between tie- and free-stall barns, they had to represent a completely different population of cows, which we believe was not likely. The present experiment was conducted with one tie-stall and one free-stall barn; therefore, presented findings may be intrinsic to the present location. However, when multiple locations are utilized other confounding effects are also included such as management practices, milking frequency, diet characteristics, and so on. Therefore, it becomes extremely challenging, expensive, and laborious to include enough replications of each possible farm characteristic to have multiple locations. Trials are frequently published with one source of a particular feed vs. a single source of another feed. Free-stall barns with headlocks are pretty standard and probably vary less from barn to barn than feeds from different sources.
To our knowledge no other study has compared feed choice behavior in tie- vs. free-stall barns. We hypothesized that cows free to move alongside the feed bunk can and will sort to a greater extent than cows tied to a specific location. The present study was designed to represent an actual farm comparison where differences between tie- and free-stall barns extended to more than solely individually vs. group-fed animals. In doing so our study does not explain what causes the increase in feed selection against longer particles when cows were fed as a group in a free-stall barn compared with individually fed in tie-stall barn. Although, cows in both facilities were fed the same diet, slightly different management practices such as feeding once a day vs. twice a day may have also contributed to the observed differences. DeVries et al. (2005) compared feeding behavior of lactating dairy cows fed once, twice, or 4 times a day by measuring dietary NDF concentration in the feed bunk throughout the day. As time progressed NDF dietary concentration increased in a curvilinear fashion, and $24 \mathrm{~h}$ after morning feeding it was higher for cows fed once a day compared with cows fed twice a day (DeVries et al., 2005). Although in the present experi- 


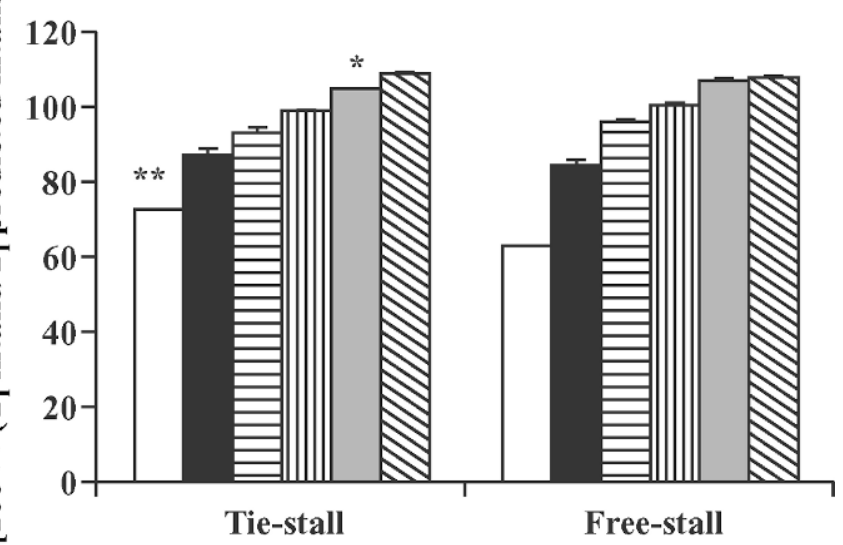

Treatment
Figure 2. Effect of facility on feed selection $\left[\left(100 \times\left(\mathrm{Y}_{\mathrm{i}}\right.\right.\right.$ intake/ $\mathrm{Y}_{\mathrm{i}}$ predicted intake)] activity (as-fed basis). Screens are labeled from left (long material) to right (fine material) as $\mathrm{Y}_{1}$ (white), $\mathrm{Y}_{2}$ (black), $\mathrm{Y}_{3}$ (horizontal lines), $\mathrm{Y}_{4}$ (vertical lines), $\mathrm{Y}_{5}$ (grey), and pan (diagonal lines), respectively. Free-stall data include 18 additional cows not present in tie-stall values. Comparison between tie- vs. free-stall barns at $* * P=0.03, * P=0.06$.

ment cows in the tie-stall were fed twice a day and cows in the tie-stall were fed once a day, the time interval between feedings in the tie-stall barn was only $4 \mathrm{~h}$. Moreover, the afternoon feeding corresponded with the milking time; therefore, cows were not present or were returning from the milking parlor. The second feeding did not involve mixing a new diet and consisted exclusively with dumping a tub of TMR in the feed bunk of the cow. Therefore, we believe that the effect of feeding frequency was muted or at least strongly attenuated in the present experiment.

Tie-stall data were utilized to verify possible correlations between feed selection and milk production and composition. When fed in the tie-stall, on average, cows produced $31.1 \mathrm{~kg}$ of milk, $944 \mathrm{~g}$ of protein, and 1,173 $\mathrm{g}$ of fat daily. There were no significant $(P>0.08)$ correlations between individual cow feed selection of each screen measured in tie-stalls and milk production or composition $(\mathrm{r}<0.25)$. Although it was not an objective of this experiment, the correlation between extent of feed selection and amount of refusal was also tested.
The amount of feed refused expressed as a percentage of the feed offered ranged from 6 to $33 \%$. Intake of $\mathrm{Y}_{1}$ expressed as a percentage of predicted intake was negatively correlated $(\mathrm{r}=-0.57, P<0.001)$ with the amount of feed refused expressed as a percentage of feed offered. Therefore, cows sorted more against longer particles when overfed. Similarly, increasing the amount of corn stover offered to dairy cattle, to allow more refusal than the conventional 5 to $10 \%$ above requirements, increased selection in favor of more palatable portion of the plant such as the leaves (Methu et al., 2001). Therefore, gross overfeeding of cows should be avoided if feed selection-induced acidosis is likely to occur.

Cows fed as a group in a free-stall barn sorted against longer or in favor of shorter particles to a greater extent than cows fed individually in a tie-stall barn. Feed selection estimates made with individually fed cows are likely to underestimate average feed selection in a freestall barn.

\section{ACKNOWLEDGMENTS}

The authors thank the barn crew of the University of Wisconsin Emmons Blaine Dairy Cattle Research Center located in Arlington for their help. This project was supported by USDA formula funding as part of regional project NC-1009.

\section{REFERENCES}

American National Standards Institute. 1998. Method of determining and expressing particle size of chopped forage materials by screening. ASAE S424.1. Page 578. ASAE, St. Joseph, MI.

DeVries, T. J., M. A. G. von Keyserlingk, and K. A. Beauchemin. 2005. Frequency of feed delivery affects the behavior of lactating dairy cows. J. Dairy Sci. 88:3553-3562.

Krause, K. M., and D. K. Combs. 2003. Effects of forage particle size, forage source, and grain fermentability on performance and ruminal pH in midlactation cows. J. Dairy Sci. 86:1382-1397.

Leonardi, C., and L. E. Armentano. 2003. Effect of quantity, quality, and length of alfalfa hay on selective consumption by dairy cows. J. Dairy Sci. 86:557-564.

Leonardi, C., F. Giannico, and L. E. Armentano. 2005. Effect of water addition on selective consumption (sorting) of dry diets by dairy cattle. J. Dairy Sci. 88:1043-1049.

Methu, J. N., E. Owen, A. L. Abate, and J. C. Tanner. 2001. Botanical and nutritional composition of maize stover, intakes and feed selection by dairy cattle. Livest. Prod. Sci. 71:87-96. 